\title{
Mössbauer Spectroscopy and Magnetic Properties of $\mathrm{Bi}_{0.8} \mathrm{Ca}_{0.2-x} \mathrm{Sr}_{x} \mathrm{FeO}_{3}$ Nanoparticles by Sol-gel Method
}

\author{
Jin Pei LIN 1, 2, Ze Ping GUO ${ }^{1}$, Qing LIN ${ }^{1,2}{ }^{*}$, Yun Long WANG ${ }^{1}$, Kang Ling HUANG ${ }^{1}$, \\ Yun HE ${ }^{1,3}$
}

${ }^{1}$ College of Physics and Technology, Guangxi Normal University, Guilin 541004, P.R.China

${ }^{2}$ Guangxi Key Laboratory of Nuclear Physics and Nuclear Technology, Guangxi Normal University, Guilin 541004, P.R.China

${ }^{3}$ Sate Key Laboratory for Chemistry and Molecular Engineering of Medicinal Resources, Guangxi Normal University, Guilin 541004, P.R.China

crossref http://dx.doi.org/10.5755/j01.ms.25.2.19456

\section{Received 10 November 2017; accepted 18 February 2018}

\begin{abstract}
Doping at A/B-sites can effectively improve the physical properties of perovskite ferrites. In this study, the performance of $\mathrm{Bi}_{0.8} \mathrm{Ca}_{0.2-x} \mathrm{Sr}_{x} \mathrm{FeO}_{3}$ was investigated using the sol-gel autocombustion method. The results show that with an increase in $x$ value, the grain size first increases and then decreases. With an increase in the doping concentration, the reunion phenomenon reduces, but the smoothness and flatness of the samples are also destroyed. Moreover, with increasing $\mathrm{Sr}^{2+}$ concentration, particle growth is inhibited, resulting in smaller particle sizes. When the $\mathrm{Sr}^{2+}$ concentration increases to a certain value, the environment becomes advantageous for particle growth and therefore the particle size increases. For $x=0.13$, small particles are obtained. With increasing $\mathrm{Sr}^{2+}$ concentration, the spatial modulation of the spin structure is destroyed, the lattice distorts, and the magnetic force is freed. Mössbauer spectrum measurements shows that when the $\mathrm{Ca}^{2+}$ concentration is greater than the $\mathrm{Sr}^{2+}$ concentration, $\mathrm{Sr}^{2+}$ ions replace $\mathrm{Ca}^{2+}$ ions; as a result, A-A magnetic superexchange diminishes, leading to a decrease in the hyperfine field. Appropriate doping of $\mathrm{BiFeO}_{3}$ can improve its coercivity and refine its grains and result in a larger magnetic force.

Keywords: Sr-substituted, perovskite, structure, magnetic properties, Mössbauer.
\end{abstract}

\section{INTRODUCTION}

A multiferroic material can simultaneously show two or more basic magnetic properties including ferromagnetism, antiferromagnetism, and ferroelectricity. One such novel material is elastic iron [1-3]. Multiferroic materials have attracted much research attention owing to their interesting properties. At present, they are widely used in the field of information storage, microwave, sensors, and converters [4-5]. $\mathrm{BiFeO}_{3}$ is a multiferroic material with a rhombohedral distorted perovskite structure. It is a rare material that simultaneously shows weak ferroelectricity $\left(T_{\mathrm{C}} \approx 830^{\circ} \mathrm{C}\right)$ and ferromagnetism $\left(\mathrm{T}_{\mathrm{N}} \approx 370{ }^{\circ} \mathrm{C}\right) \quad[6-8]$; therefore, it has been studied extensively. However, it is difficult to prepare pure-phase $\mathrm{BiFeO}_{3}$ because $\mathrm{Bi}$ can volatilize relatively easily during synthesis and the $\mathrm{Fe}$ valence fluctuates. At present, $\mathrm{BiFeO}_{3}$ is mainly synthesized by the hydrothermal method [9], solgel [10], and coprecipitation method [11]. As $\mathrm{Bi}$ in $\mathrm{BiFeO}_{3}$ can volatilize easily, a second phase such as $\mathrm{Bi}_{25} \mathrm{FeO}_{40}$ or $\mathrm{Bi}_{2} \mathrm{Fe}_{4} \mathrm{O}_{9}$ is formed. In addition, the large leakage current of $\mathrm{BiFeO}_{3}$ makes it difficult to achieve good magnetoelectric properties. Doping can reduce the volatility of $\mathrm{Bi}$ and greatly improve the magnetoelectric properties of $\mathrm{BiFeO}_{3}$ [12]. Many studies have reported the doping of $\mathrm{BiFeO}_{3}$ at the $\mathrm{A}$ site by alkaline earths such as $\mathrm{Ca}, \mathrm{Mg}, \mathrm{Sr}$, and $\mathrm{Ba}[13,14,15]$. However, few studies have reported on double-doping at the A site by alkaline

\footnotetext{
* Corresponding author. Tel.: +86-773-5840785; fax: +86-773-5811173 E-mail address: hy@gxnu.edu.cn (Q. Lin)
}

earths, such as doping using $\mathrm{Ca}$ and $\mathrm{Mg}, \mathrm{Ca}$ and $\mathrm{Sr}$, or $\mathrm{Ba}$ and $\mathrm{Ca}$.

In this study, we aimed to investigate the performance of $\mathrm{Bi}_{0.8} \mathrm{Ca}_{0.2-x} \mathrm{Sr}_{x} \mathrm{FeO}_{3}(x=0.04 \sim 0.20)$ by using the sol-gel autocombustion method. This study had three main objectives: (1) to use the sol-gel autocombustion method to investigate the influence of the double-doping content of alkaline earth ions on the structure by synthetizing a sample with a single-phase spinel structure; (2) to investigate the influence of the doping content by synthesizing homogeneously distributed and wellcrystallized ferrite nanopowder samples; and (3) to investigate the magnetic properties of samples with different double-doping contents of alkaline earth ions at the A site by Mössbauer spectroscopy and to confirm the magnetic behavior of $\mathrm{Bi}_{0.8} \mathrm{Ca}_{0.2-x} \mathrm{Sr}_{x} \mathrm{FeO}_{3}$ nanoferrites.

\section{EXPERIMENTAL SECTION}

\subsection{Sample synthesis}

Fig. 1 shows the synthesis route of $\mathrm{Bi}_{0.8} \mathrm{Ca}_{0.2-x} \mathrm{Sr}_{x} \mathrm{FeO}_{3}$ powder prepared using the polyacrylamide sol-gel method. Identical mol amounts of $\mathrm{Bi}\left(\mathrm{NO}_{3}\right)_{3} \cdot 5 \mathrm{H}_{2} \mathrm{O}$ and $\mathrm{Fe}\left(\mathrm{NO}_{3}\right)_{3} \cdot 9 \mathrm{H}_{2} \mathrm{O}$ are added to dilute nitric acid $(1.6 \mathrm{~mol} / \mathrm{L})$. Then, some ethylenediamine tetraacetic acid is added as a complexing agent. Appropriate amounts of glucose $(20 \mathrm{~g} / 100 \mathrm{ml}), \mathrm{Ca}\left(\mathrm{NO}_{3}\right)_{2} \cdot 6 \mathrm{H}_{2} \mathrm{O}$, and $\mathrm{Sr}\left(\mathrm{NO}_{3}\right)_{2}$ are added according to the proportion, and the mixture is stirred constantly. Then, acrylamide monomer with metal cations is added in the molar ratio of $1: 9$, and the precursor 
reaction liquids are mixed completely. The precursor solution is heated at $70{ }^{\circ} \mathrm{C}$ in a water bath for $5-10 \mathrm{~min}$ to obtain a transparent solution. Then, an appropriate amount of ammonia is added to the transparent solution to adjust its $\mathrm{pH}$ value to $\approx 3$. Finally, the solution is heated at $80{ }^{\circ} \mathrm{C}$ for $5-7 \mathrm{~h}$ in the water bath until a dry wet gel is obtained. The wet gel is placed in a drying chamber and dried at $120{ }^{\circ} \mathrm{C}$ for $5 \mathrm{~h}$ to obtain a dry gel. Then, the dry gel is combusted in air by adding drops of anhydrous ethanol propellant to obtain a fluffy powder. This powder is ground and placed in a muffle furnace, in which it is calcined at $600{ }^{\circ} \mathrm{C}$ for $3 \mathrm{~h}$ to obtain a fluffy yellow mud powder.

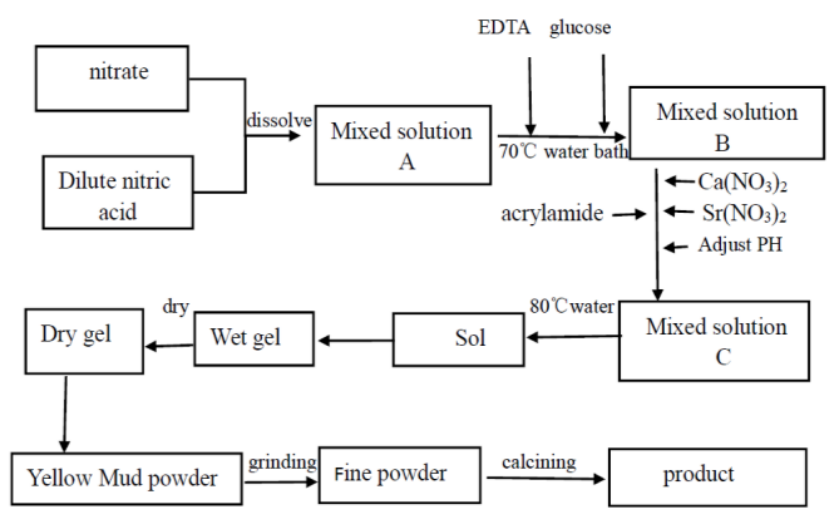

Fig. 1. Synthesis route of $\mathrm{Bi}_{0.8} \mathrm{Ca}_{0.2-x} \mathrm{Sr}_{x} \mathrm{FeO}_{3}$ powder by polyacrylamide sol-gel method

\subsection{Sample characterization}

The crystalline structure was investigated by $\mathrm{x}$-ray diffraction (XRD, Rigaku D/max-2500V/PC) with $\mathrm{Cu} \mathrm{K \alpha}$ radiation $(\lambda=0.15405 \mathrm{~nm})$. The micrographs were obtained by scanning electron microscopy (SEM, NoVa ${ }^{\mathrm{TM}}$ Nano SEM 430). The Mössbauer spectrum was performed at room temperature, using a conventional Mössbauer spectrometer (MS, Fast Com Tec PC-moss II), in constant acceleration mode. The $\gamma$-rays were provided by a ${ }^{57} \mathrm{Co}$ source in a rhodium matrix. Magnetization measurements were carried out with superconducting quantum interference device (MPMS-XL-7, Quantum Design) at room temperature.

\section{RESULTS AND DISCUSSION}

\subsection{Structure analysis of $\mathrm{Bi}_{0.8} \mathrm{Ca}_{0.2-x} \mathrm{Sr}_{x} \mathrm{FeO}_{3}$}

Many studies have reported on the doping of $\mathrm{BiFeO}_{3}$ at the A site by alkaline earths such as $\mathrm{Ca}, \mathrm{Mg}, \mathrm{Sr}$, and $\mathrm{Ba}$. For example, Khomchenko et al. [15] investigated the influence of different $\mathrm{Ca}^{2+}$ and $\mathrm{Sr}^{2+}$ doping ratios on the structure analysis of $\mathrm{Bi}_{0.7} \mathrm{~A}_{0.3} \mathrm{FeO}_{3} \quad\left(\mathrm{~A}=\mathrm{Ca}^{2+}, \quad \mathrm{Sr}^{2+}\right)$ samples. However, few studies have reported on doubledoping at the A Site by alkaline earths, such as doping using $\mathrm{Ca}$ and $\mathrm{Sr}$. Fig. 2 shows the room-temperature $\mathrm{X}$-ray diffraction pattern of $\mathrm{Bi}_{0.8} \mathrm{Ca}_{0.2-x} \mathrm{Sr}_{x} \mathrm{FeO}_{3} \quad(x=0.04 \sim 0.20)$ calcined at $600{ }^{\circ} \mathrm{C}$ for $3 \mathrm{~h}$. All diffraction peaks appear to be attributable to a pure phase, and all of them conform to the standard diffraction peaks (JCPDS card no. 861518) of $\mathrm{BiFeO}_{3}$ with perovskite structure. The impurity in these samples is undetectable, and it shows no significant change when the doping content is increased from 0.04 to 0.20 , as shown in Fig. 2 a; this result agrees well with that of Chauhan's study [2].

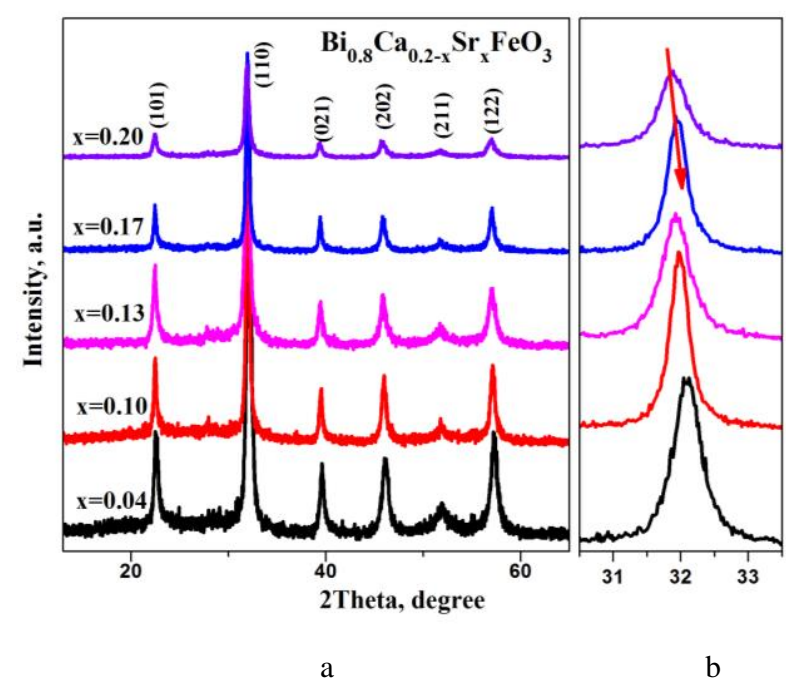

Fig. 2. XRD patterns of various contents for $\mathrm{Bi}_{0.8} \mathrm{Ca} 0.2-x \mathrm{Sr}_{x} \mathrm{FeO}_{3}$ samples calcined at $600{ }^{\circ} \mathrm{C}$ for $3 \mathrm{~h}$

The diffraction peak changes with $\mathrm{Ca}^{2+}$ and $\mathrm{Sr}^{2+}$ codoping; however, no clear impurity phase with good crystallinity can be seen. The diffraction peak trends toward low $2 \theta$ angles, as shown in Fig. 2 a. This may be due to the replacement radius of $\mathrm{Sr}^{2+}\left(R_{\mathrm{Sr}}=0.118 \mathrm{~nm}\right)$ being greater than that of $\mathrm{Ca}^{2+}\left(R_{\mathrm{Ca}}=0.1 \mathrm{~nm}\right)$ owing to the distortion of the crystal structure $[13,14] . \mathrm{Ca}^{2+}$ and $\mathrm{Sr}^{2+}$ ions can enter the $\mathrm{BiFeO}_{3}$ perovskite crystal structure and form a solid solution; this is consistent with the conclusion of Khomchenko et al. [15]. Furthermore, with an increase in $x$ value, the diffraction peak intensity of the samples gradually decreases, because codoping by alkaline earth ions reduces the crystalline effect. It should be noted that the half high width of the diffraction peak first increases and then decreases with an increase in $x$ value. When only $\mathrm{Sr}$ is doped $(x=0.2)$, the half high width of the diffraction peak tends to increase again [16].

Fig. $2 \mathrm{~b}$ shows an enlarged view of the (110) peaks of $\mathrm{Bi}_{0.8} \mathrm{Ca}_{0.2-x} \mathrm{Sr}_{x} \mathrm{FeO}_{3}$ nanoferrites. This figure shows that all diffraction peaks widen and move in the direction of increasing diffraction angle with increasing amounts of $\mathrm{Ca}$. Fig. $2 \mathrm{~b}$ also shows the lattice parameters for $\mathrm{Bi}_{0.8} \mathrm{Ca}_{0.2}$ ${ }_{x} \mathrm{Sr}_{x} \mathrm{FeO}_{3}(x=0.04 \sim 0.20)$. With increasing proportion of doped $\mathrm{Sr}$, the diffraction peaks markedly move in the increasing $2 \theta$ direction; this agrees well with Khomchenko's results [17].

The Scherrer formula is given as follows [18, 19]:

$D=K \lambda / \beta \cos \theta$,

where $K$ is the Scherrer constant; $\beta$ is the half high width of the peak; $D$ is the grain size; $\lambda$ is the $\mathrm{X}$-ray wavelength; and $\theta$ is the diffraction angle. The wider the peak, the smaller the grains can be, and the narrower the peak, the bulkier the grains can be. Therefore, the grain size first increases and then decreases with an increase in $x$ value. As mentioned above, when only $\mathrm{Sr}$ is doped $(x=0.2)$, it tends to increase, as shown in Fig. 3. 


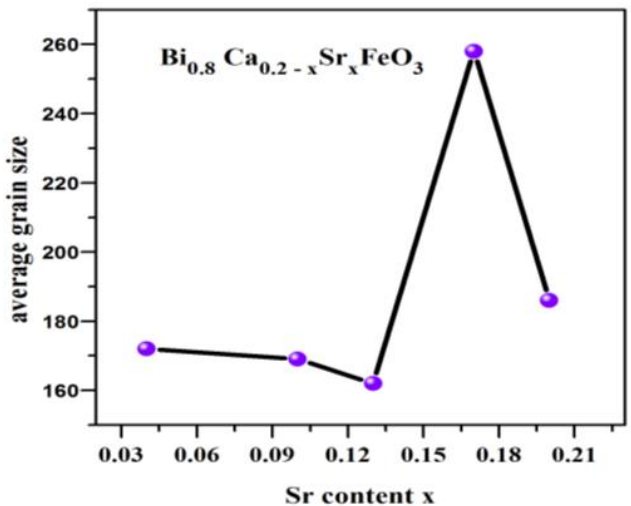

Fig. 3. Change in average grain size with proportion of doped $\mathrm{Sr}$ value

\subsection{SEM microstructure studies of $\mathrm{Bi}_{0.8} \mathrm{Ca}_{0.2-}$ ${ }_{x} \mathrm{Sr}_{x} \mathrm{FeO}_{3}$}

Fig. 4 shows scanning electron microscope (SEM) images of $\mathrm{Bi}_{0.8} \mathrm{Ca}_{0.2-x} \mathrm{Sr}_{x} \mathrm{FeO}_{3}$ calcined at $600{ }^{\circ} \mathrm{C}$ for $3 \mathrm{~h}$. The particle size of the samples decreases and then increases with an increase in the doping amount, and the reunion phenomenon reduces. This suggests that an increase in the $\mathrm{Sr}^{2+}$ concentration inhibits particle growth, resulting in smaller particle size in the samples. When the $\mathrm{Sr}^{2+}$ concentration increases to a certain value, the environment becomes advantageous for particle growth and therefore the particle size increases. Therefore, the grain size can be refined effectively by controlling the $\mathrm{Sr}^{2+}$ concentration in the samples $[20,21]$.
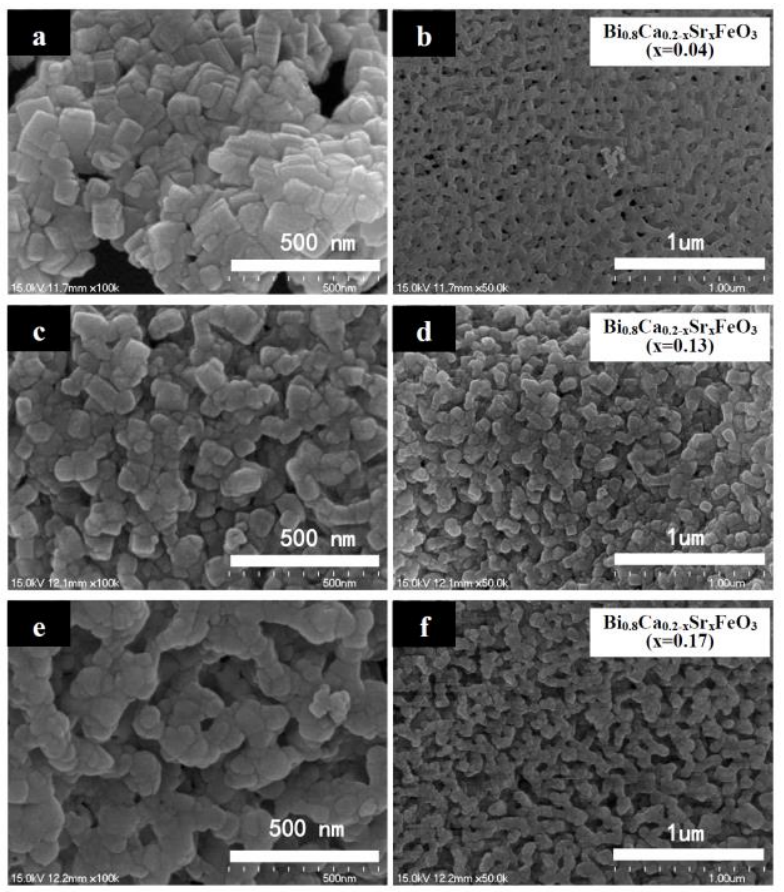

Fig. 4. SEM micrographs of $\mathrm{Bi}_{0.8} \mathrm{Ca} 0.2-x \mathrm{Sr}_{x} \mathrm{FeO}_{3}$ calcined at $600{ }^{\circ} \mathrm{C}$ for $3 \mathrm{~h}$

A particle size distribution analysis software is used to obtain a histogram of the sample's particle size distribution, as shown in Fig. 5. For $x=0.04$, the particle size is mainly concentrated in the range of $71-89 \mathrm{~nm}$. Then, for $x=0.13$, the particle size obviously decreases to the range of $60-71 \mathrm{~nm}$. However, for $x=0.17$, the particle size increases and is mainly concentrated in the range of $69-87 \mathrm{~nm}$. These results indicate that with an increase in $\mathrm{Sr}^{2+}$ concentration, the particle size first decreases and then increases; these results are consistent with the XRD results $[22,23]$.

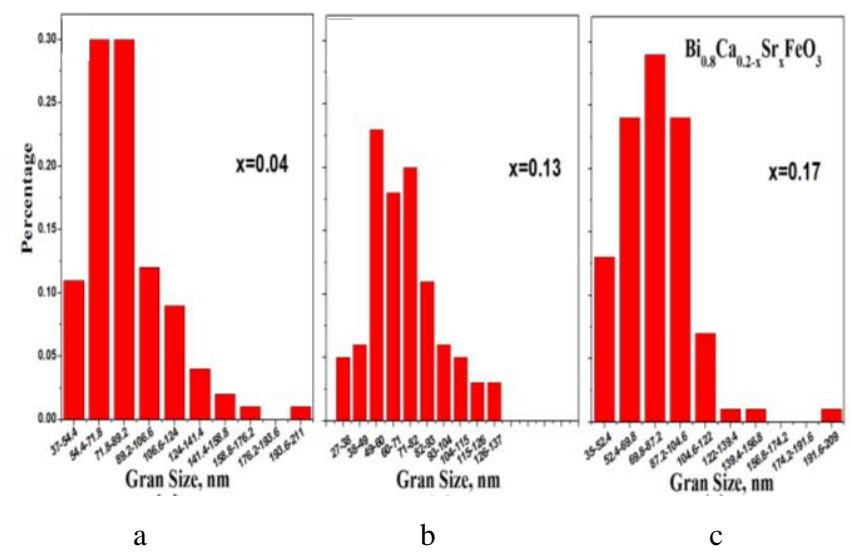

Fig. 5. Histogram of $\mathrm{Bi}_{0.8} \mathrm{Ca}_{0.2-x} \mathrm{Sr}_{x} \mathrm{FeO}_{3} \quad(x=0.04,0.13,0.17)$ samples' particle size distribution

\subsection{Magnetic studies of $\mathrm{Bi}_{0.8} \mathrm{Ca}_{0.2-x} \mathrm{Sr}_{x} \mathrm{FeO}_{3}$}

Fig. 6 shows the magnetic hysteresis curves of $\mathrm{Bi}_{0.8} \mathrm{Ca}_{0.2-x} \mathrm{Sr}_{x} \mathrm{FeO}_{3}(x=0.04,0.13,0.17)$ calcined at $600{ }^{\circ} \mathrm{C}$ for $3 \mathrm{~h}$. All samples almost reach saturation magnetization when the field is 10000 Oe. Table 1 shows the corresponding parameters.

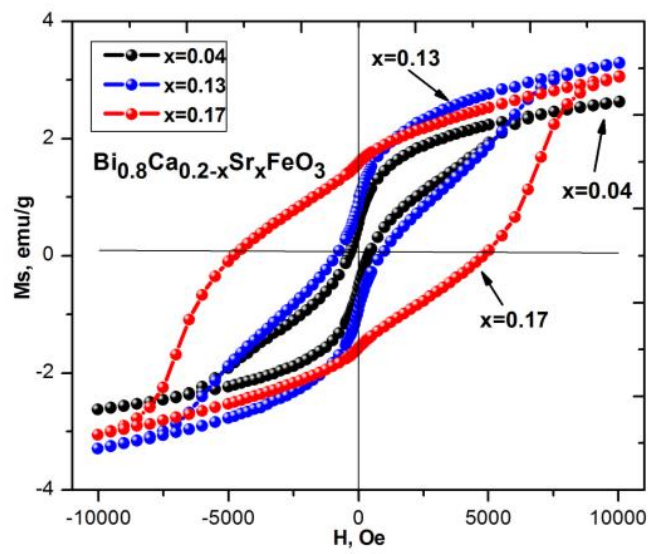

Fig. 6. Hysteresis curves of $\mathrm{Bi} 0.8 \mathrm{Ca} 0.2-\mathrm{Sr}_{x} \mathrm{FeO}_{3}$ calcined at $600{ }^{\circ} \mathrm{C}$ for $3 \mathrm{~h}$ with different $\mathrm{Ca}^{2+}$ and $\mathrm{Sr}^{2+}$ doping contents $(x=0.04,0.13,0.17)$

Table 1 shows that with $\mathrm{Sr}^{2+}$ doping, the saturation magnetization of the samples first increases and then decreases. The saturation magnetization can be expressed as follows $[16,17,24]$ :

$\sigma_{\mathrm{s}}=\frac{5585 \times n_{B}}{M}$

where $n_{\mathrm{B}}$ is the magnetic moment (unit: Bohr magneton) and $M$, the relative molecular mass. The relative molecular mass of the sample increases with increasing $\mathrm{Sr}^{2+}$ doping. Fig. 6 and Table 1 show that with an increase in $x$ value, the remanent magnetization and coercive force of the samples increase substantially. 
Table 1. Saturation magnetization $(M \mathrm{~s})$, coercivity $(H \mathrm{c})$, residual magnetization $(\mathrm{Mr})$, and magnetic moment $\left(n_{B}\right)$ of $\mathrm{Bi}_{0.8} \mathrm{Ca}_{0.2-x} \mathrm{Sr}_{x} \mathrm{FeO}_{3}$ calcined at $600^{\circ} \mathrm{C}$ for $3 \mathrm{~h}$

\begin{tabular}{|c|c|c|c|c|}
\hline Content, $x$ & $M \mathrm{~s}, \mathrm{emu} / \mathrm{g}$ & $H \mathrm{c}$, Oe & $M \mathrm{r}, \mathrm{emu} / \mathrm{g}$ & $n_{\mathrm{B}}$ \\
\hline 0.04 & 2.6222 & 376.1749 & 0.5618 & 0.1319 \\
\hline 0.13 & 3.2832 & 877.8747 & 0.9169 & 0.1659 \\
\hline 0.17 & 3.0547 & 4764.8620 & 1.5820 & 0.1534 \\
\hline
\end{tabular}

Table 2. Mössbauer parameters including isomer shift (I.S.), quadrupole splitting (Q.S.), magnetic hyperfine field (Hf), line width (Г), and absorption area $\left(\mathrm{A}_{0}\right)$ of $\mathrm{Bi}_{0.8} \mathrm{Ca}_{0.2-x} \mathrm{Sr}_{x} \mathrm{FeO}_{3}(x=0.04,0.13,0.17)$ annealed at $600{ }^{\circ} \mathrm{C}$ for $3 \mathrm{~h}$

\begin{tabular}{|c|c|c|c|c|c|}
\hline Content, $x$ & I.S., $\mathrm{mm} / \mathrm{s}$ & Q.S., $\mathrm{mm} / \mathrm{s}$ & $H_{\mathrm{hf}, \mathrm{T}}$ & $\Gamma, \mathrm{mm} / \mathrm{s}$ & $A_{0}, \%$ \\
\hline 0.04 & 0.3847 & -0.0556 & 48.9627 & 0.5969 & 10.5160 \\
\hline 0.13 & 0.2591 & 0.0070 & 48.7614 & 0.5974 & 9.4367 \\
\hline 0.17 & 0.2419 & -0.0325 & 48.8988 & 0.5604 & 18.672 \\
\hline
\end{tabular}

In particular, when $x$ value increases from 0.13 to 0.17 , the remanent magnetization increases from 0.9169 to $1.5820 \mathrm{emu} / \mathrm{g}$, respectively, and the coercive force increases more than five-fold from 877.8747 to 4764.8620 Oe, respectively. These large changes are attributable to the increase in $\mathrm{Sr}^{2+}$ content in the sample; this increase distorts the lattice, destroys the spatial modulation of the spin structure, and frees the magnetic force, resulting in a larger magnetic force [19, 25, 26].

\subsection{Mössbauer spectroscopy study of $\mathrm{Bi}_{0.8} \mathrm{Ca}_{0.2-}$ ${ }_{x} \mathrm{Sr}_{x} \mathrm{FeO}_{3}$}

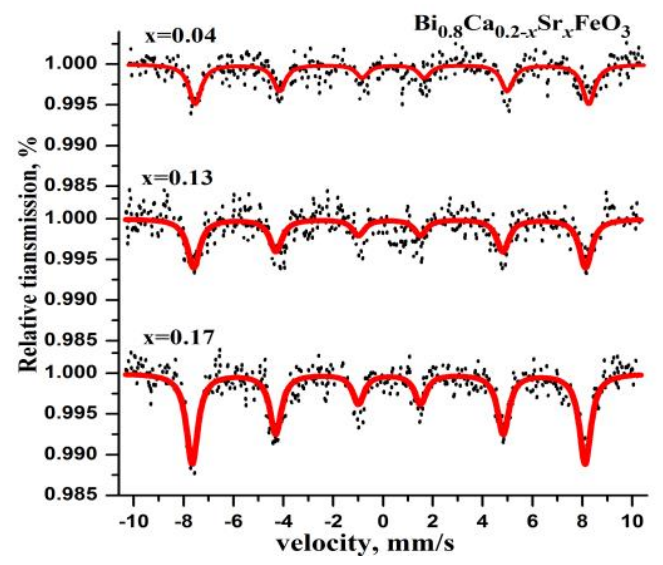

Fig. 7. Mössbauer spectra of $\mathrm{Bi}_{0.8} \mathrm{Ca}_{0.2-x} \mathrm{Sr}_{x} \mathrm{FeO}_{3}(x=0.04,0.13$, 0.17) calcined at $600{ }^{\circ} \mathrm{C}$ for $3 \mathrm{~h}$

Fig. 7 shows the Mössbauer spectra of $\mathrm{Bi}_{0.8} \mathrm{Ca}_{0.2}$ ${ }_{x} \mathrm{Sr}_{x} \mathrm{FeO}_{3}(x=0.04,0.13,0.17)$. The spectral data of all samples are analyzed used Mösswinn 3.0 software, and all spectral peaks are fitted with a set of six lines. All maps show a six-line spectrum, indicating that the samples are ferromagnetic. With an increase in $\mathrm{Sr}^{2+}$ concentration, an increasing number of black spots concentrate around the red spectrum line and the sinking peak becomes much larger.

Table 2 shows the isomeric shift (I.S.), quadrupole splitting (Q.S.), hyperfine field $\left(\mathrm{H}_{\mathrm{hf}}\right)$, line width $(\Gamma)$, and relative parameters such as absorption area $\left(\mathrm{A}_{0}\right)$ of samples that are calcined at $600{ }^{\circ} \mathrm{C}$ for $3 \mathrm{~h}$ and then naturally cooled to room temperature. From Fig. 7 and Table 2, the Mössbauer spectrum line width parameter values $(\Gamma)$, relative absorption area, lattice distribution, $\mathrm{Bi}$ ions, $\mathrm{Sr}^{2+}$ ions, and $\mathrm{Fe}^{3+}$ ions can be determined. With an increase in $\mathrm{Sr}^{2+}$ concentration, the I.S. decreases. With a change in the concentration of $\mathrm{Ca}^{2+}$ and $\mathrm{Sr}^{2+}$ ions, the distance between $\mathrm{Fe}^{3+}$ ions and $\mathrm{O}$ ions in the lattice changes. This, in turn, affects the s orbital's electron cloud overlap [18, 27, 28] and eventually leads to a change in IS. Based on literature [19], I.S. for $\mathrm{Fe}^{2+}$ ions lies in the range $0.6-1.7 \mathrm{~mm} / \mathrm{s}$, and that for $\mathrm{Fe}^{3+}$ ions lies in the range of $0.1-0.5 \mathrm{~mm} / \mathrm{s}$. The I.S. values in Table 2 indicate that iron is in the $\mathrm{Fe}^{3+}$ state. The $\mathrm{H}_{\mathrm{hf}}$ first increases and then decreases with an increase in the $\mathrm{Sr}^{2+}$ concentration. This is because when the $\mathrm{Ca}^{2+}$ concentration is greater than the $\mathrm{Sr}^{2+}$ concentration, $\mathrm{Sr}^{2+}$ ions replace $\mathrm{Ca}^{2+}$ ions; as a result, A-A magnetic superexchange diminishes, leading to a decrease in $\mathrm{H}_{\mathrm{hf}}$ $[29,30]$. When the $\mathrm{Ca}^{2+}$ concentration is smaller than the $\mathrm{Sr}^{2+}$ concentration, the opposite results are obtained. All Q.S. values of samples that show six-line magnetic peaks are very small and can be ignored. This suggests that the concentration of $\mathrm{Ca}^{2+}$ and $\mathrm{Sr}^{2+}$ ions in the $\mathrm{Bi}_{0.8} \mathrm{Ca}_{0.2-}$ ${ }_{x} \mathrm{Sr}_{x} \mathrm{FeO}_{3}$ sample has little impact on Q.S. [31]. Furthermore, the charge distribution around the nucleus of perovskite ferrite is symmetric, which could be caused by a variation in the ratio of the $\mathrm{Fe}^{2+} / \mathrm{Fe}^{3+}$ valence states $[32,33,34]$.

\section{CONCLUSIONS}

In this study, the polyacrylamide sol-gel method was used to synthesize $\mathrm{Bi}_{0.8} \mathrm{Ca}_{0.2-x} \mathrm{Sr}_{x} \mathrm{FeO}_{3}$ nanoferrites. With an increase in $x$ value, no impurity was seen in the sample. With an increase in the $\mathrm{Sr}^{2+}$ concentration, as the replacement radius of $\mathrm{Sr}^{2+}$ ions $\left(\mathrm{R}_{\mathrm{Sr}}=0.118 \mathrm{~nm}\right)$ is greater than that of $\mathrm{Ca}^{2+}$ ions $\left(\mathrm{R}_{\mathrm{Ca}}=0.1 \mathrm{~nm}\right)$, the crystal structure distorts and the diffraction peaks shift toward low angles. In addition, with an increase in $\mathrm{Sr}^{2+}$ concentration, the half high width of the diffraction peak first increases, then decreases, and finally increases again. These results show that changes in the $\mathrm{Ca}^{2+}$ and $\mathrm{Sr}^{2+}$ concentrations can directly affect grain growth. Doping can reduce the reunion phenomenon and also reduce the smoothness and flatness of the grain surface. Mössbauer spectrum measurements show that when the $\mathrm{Ca}^{2+}$ concentration is greater than the $\mathrm{Sr}^{2+}$ concentration, $\mathrm{Sr}^{2+}$ ions replace $\mathrm{Ca}^{2+}$ ions; as a result, A-A magnetic superexchange diminishes, leading to a decrease in $\mathrm{H}_{\mathrm{hf}}$. With an increase in $\mathrm{Sr}^{2+}$ concentration, the coercive force of the sample changes greatly. As the $\mathrm{Ca}^{2+}$ 
and $\mathrm{Sr}^{2+}$ concentrations in the sample change, the highly helical structure is damaged and the magnetic force is freed this can result in an increase in the magnetic force. Appropriate doping of $\mathrm{BiFeO}_{3}$ can improve its $\mathrm{Hc}$ and refine its grains and result in a larger magnetic force.

\section{Acknowledgments}

This work was financially supported by the National Natural Science Foundation of China (NO.11364004,11647309,11547307,11164002) and Innovation Project of Guangxi Graduate Education under Grant (NO.YCSW2017097). J.P. Lin, Z.P. Guo and Q. Lin contributed equally to this work. Y. He, Q. Lin and K.L. Huang participated in experimental design. J.P. Lin, Z.P. Guo and Y.L. Wang collects data. Q. Lin and Y. He is co-corresponding authors contributed equally to this study. All authors discussed the results and commented on the manuscript. And the project was funded by State Key Laboratory for Chemistry and Molecular Engineering of Medicinal Resources.

\section{REFERENCES}

1. Niu, F., Gao, T., Qin, L., Chen, Z., Huang, Q., Zhang, N., Wang, S., Sun, X., Huang, Y. Polyvinyl Alcohol (Pva)-Assisted Synthesis of $\mathrm{BiFeO}_{3}$ Nanoparticles for Photo Catalytic Applications Journal of New Materials for Electrochemical Systems 18 (2) 2015: pp. 69-73.

2. Chauhan, S., Kumar, M., Chhoker, S., Katyal, S.C., Singh, M. Substitution Driven Structural and Magnetic Transformation in Ca-Doped $\mathrm{BiFeO}_{3}$ Nanoparticles $R S C$ Advances 6 (49) 2016: pp. 43080-43090. https://doi.org/10.1039/C6RA02316A

3. Tlemçani, T.S., Bahraoui, T.E., Taibi, M., Belayachi, A., Schmerber, G., Dinia, A., Abd-Lefdil, M. Abd-Lefdil. Effect of $\mathrm{Nd}$ Substitution on Physical Properties of Multiferroic Compound $\mathrm{BiFeO}_{3}$ Journal of Sol-Gel Science and Technology 73 (3) 2015: pp. 673-678. https://doi.org/10.1007/s10971-015-3654-Z

4. Layek, S., Verma, H.C., Garg, A. Enhancement in Magnetic Properties of $\mathrm{Ba}-$ Doped $\mathrm{BiFeO}_{3}$ Ceramics by Mechanical Activation Journal of Alloys Compounds 651 2015: pp. $294-301$.

https://doi.org/10.1016/j.jallcom.2015.08.057

5. Lazenka, V.V., Zhang, G., Vanacken, J., Makoed, I.I., Ravinski, A.F., Moshchalkov, V.V. Corrigendum: Structural Transformation and Magnetoelectric Behaviour in $\mathrm{Bi}_{1-X} \mathrm{Gd}_{x} \mathrm{FeO}_{3}$ Multiferroics Journal of Physics D Applied Physics 45 2012: pp. 125002. https://doi.org/10.1088/0022-3727/45/12/125002

6. Tabares Muñoz, C., Rivera, J.P., $\quad$ Bezinges, A., Monnier, A., Schmid, H. Measurement of the Quadratic Magnetoelectric Effect on Single Crystalline $\mathrm{BiFeO}_{3}$ Japanese Journal of Applied Physics 24 (S2)

1985: pp. $1051-1053$. https://doi.org/10.7567/JJAPS.24S2.1051

7. Fischer, P., Polomska, M., Sosnowska, I., Szymanski, M. Temperature Dependence of the Crystal and Magnetic Structures of $\mathrm{BiFeO}_{3}$ Journal of Physics C Solid State Physics 13 (10) 2000: pp. 1931-1940. https://doi.org/10.1088/0022-3719/13/10/012

8. Schmid, H. Multi-Ferroic Magnetoelectrics Ferroelectrics 162 (1) 1994: pp. 665-685. https://doi.org/10.1080/00150199408245120
9. Chen, L., Ren, W., Zhu, W., Ye, Z.G., Shi, P., Chen, X., Wu, X., Yao, X.Improved Dielectric and Ferroelectric Properties in Ti-Doped $\mathrm{BiFeO}_{3}-\mathrm{PbTiO}_{3}$ Thin Films Prepared by Pulsed Laser Deposition Thin Solid Films 518 (6) 2010: pp. $1637-1640$. https://doi.org/10.1016/j.tsf.2009.11.072

10. Brinkman, K., Iijima, T., Nishida, K., Katoda, T., Funakubo, H. The Influence of Acceptor Doping on the Structure and Electrical Properties of Sol-Gel Derived $\mathrm{BiFeO}_{3}$ Thin Films Ferroelectrics 357 (1) 2007: pp. $35-40$. https://doi.org/10.1080/00150190701527597

11. Yotburut, B., Yamwong, T., Thongbai, P., Maensiri, S. Synthesis and Characterization of Coprecipitation-Prepared La-Doped $\mathrm{BiFeO}_{3}$ Nanopowders and Their Bulk Dielectric Properties Japanese Journal of Applied Physics 53 (53) 2014: pp. $1347-4065$. https://doi.org/10.7567/JJAP.53.06JG13

12. Gaur, A., Singh, P., Choudhary, N., Kumar, D., Shariq, M., Singh, K., Kaur, D. Structural, Optical and Magnetic Properties of Nd-Doped $\mathrm{BiFeO}_{3}$ Thin Films Prepared by Pulsed Laser Deposition Physica B Condensed Matter 406 (10) 2011: pp. 1877-1882. https://doi.org/10.1016/j.physb.2011.02.046

13. Zhang, S.T., Zhang, Y., Lu, M.H., Du, C.L., Chen, Y.F., Liu, Z.G., Zhu, Y.Y., Ming, N.B. Substitution-Induced Phase Transition and Enhanced Multiferroic Properties of $\mathrm{Bi}_{1-x} \mathrm{La}_{x} \mathrm{FeO}_{3}$ Ceramics Applied Physics Letters 88 (16) 2006: pp. 162901. https://doi.org/10.1063/1.2195927

14. Wu, M.S., Huang, Z.B., Han, C.X., Yuan, S.L., Lu, C.L., Xia, S. C. Enhanced Multiferroic Properties of $\mathrm{BiFeO}_{3}$ Ceramics by $\mathrm{Ba}$ and High-Valence $\mathrm{Nb}$ Co-Doping Solid State Communications 152 (24) 2012: pp. 2142-2146. https://doi.org/10.1016/j.ssc.2012.09.005

15. Khomchenko, V.A., Kiselev, D.A., Vieira, J.M., Jian, L., Kholkin, A.L., Lopes, A.M.L., Pogorelov, Y.G., Araujo, J.P., Maglione., M. Effect of Diamagnetic Ca, Sr, $\mathrm{Pb}$, and $\mathrm{Ba}$ Substitution on the Crystal Structure and Multiferroic Properties of the $\mathrm{BiFeO}_{3}$, Perovskite Journal of Applied Physics 103 (2) 2008: pp. 024105. https://doi.org/10.1063/1.2836802

16. Yuan, G.L., Wing, Or.S., Chan, H.L.W. Structural Transformation and Ferroelectric Paraelectric Phase Transition in $\mathrm{Bi}_{1-x} \mathrm{La}_{x} \mathrm{FeO}_{3}(x=0-0.25)$ Multiferroic Ceramics Journal of Physics D Applied Physics 40 (40) 2007: pp. $1196-1200$. https://doi.org/10.1088/0022-3727/40/4/043

17. Khomchenko, V.A., Kiselev, D.A., Selezneva, E.K., Vieira, J.M., Lopes, A.M.L., $\quad$ Pogorelov, Y.G., Araujo, J.P., Kholkin, A.L. Weak Ferromagnetism in Diamagnetically-Doped $\mathrm{Bi}_{1-x} \mathrm{~A}_{x} \mathrm{FeO}_{3},(\mathrm{~A}=\mathrm{Ca}, \mathrm{Sr}, \mathrm{Pb}, \mathrm{Ba})$ Multiferroics Materials Letters 62 (12) 2008: pp. $1927-1929$. https://doi.org/10.1016/j.matlet.2007.10.044

18. Ahmed, M.A., El-Khawlani, A.A. Enhancement of the Crystal Size and Magnetic Properties of Mg-Substituted Co Ferrite Journal of Magnetism and Magnetic Materials 9 (321) 2009: pp. 1959- 1963. https://doi.org/10.1016/j.jmmm.2008.12.021

19. Kumar, S., Farea, A.M.M., Batoo, K.M., Chan, G.L., Koo, B.H., Yousef, A. Alimuddin.Mössbauer Studies of $\mathrm{Co}_{0.5} \mathrm{Cd}_{x} \mathrm{Fe}_{2.5-x} \mathrm{O}_{4} \quad(0.0 \leqslant \mathrm{x} \leqslant 0.5) \quad$ Ferrite Physica $B$ Condensed Matter 403 (s19-20) 2008: pp. 3604-3607. https://doi.org/10.1016/j.physb.2008.06.001 
20. Widatallah, H.M., Al-Mamari, F.A.S., Al-Saqri, N.A.M., Gismelseed, A.M., Al-Omari, I.A., Al-Shahumi, T.M.H., Alhaj, A.F., Abo El Ata, A.M., Elzain, M.E. Mössbauer and Magnetic Studies of $\mathrm{Mg}_{1+2 x} \mathrm{Sb}_{x} \mathrm{Fe}_{2-3 x} \mathrm{O}_{4}$ Spinel Ferrites Materials Chemistry and Physics 140 (1)

2013: pp. $97-103$.

https://doi.org/10.1016/j.matchemphys.2013.03.005

21. Hashim, M., Meena, S.S., Kotnala, R.K., Shirsath, S.E., Bhatt, P., Kumar, S., Şentürk, E., Kumar, R., Gupta, N., Alimuddin. Exploring the Structural, Mössbauer and Dielectric Properties of $\mathrm{Co}^{2+}$, Incorporated $\mathrm{Mg}_{0.5} \mathrm{Zn}_{0.5-x} \mathrm{Co}_{x}$ $\mathrm{Fe}_{2} \mathrm{O}_{4}$, Nanocrystalline Ferrite Journal of Magnetism Magnetic Materials 360 2014: pp. 21-33. https://doi.org/10.1016/j.jmmm.2014.01.047

22. Lin, Y.H., Jiang, Q., Wang, Y., Nan, C.W., Chen, L., $\mathbf{Y u}, \mathbf{J}$. Enhancement of Ferromagnetic Properties in $\mathrm{BiFeO}_{3}$ Polycrystalline Ceramic by La Doping Applied Physics Letters 90 (17) 2007: pp. 172507. https://doi.org/10.1063/1.2732182

23. Zhang, S., Luo, W., Wang, D., Ma, Y. Phase Evolution and Magnetic Property of $\mathrm{Bi}_{1-x} \mathrm{Dy}_{x} \mathrm{FeO}_{3}$ Ceramics Materials Letters 63 (21) 2009: pp. 1820-1822. https://doi.org/10.1016/j.matlet.2009.05.056

24. Yuan, G.L., Or, S.W., Chan, H.L.W., Liu, Z. G. Reduced Ferroelectric Coercivity in Multiferroic $\mathrm{Bi}_{0.825} \mathrm{Nd}_{0.175} \mathrm{FeO}_{3}$ Thin Film Journal of Applied Physics 101 (2) 2007: pp. 024106. https://doi.org/10.1063/1.2423228

25. Gao, F., Cai, C., Wang, Y., Dong, S., Qiu, X.Y., Yuan, G.L., Liu, J.M. Preparation of La-Doped $\mathrm{BiFeO}_{3}$ Thin Films with $\mathrm{Fe}^{2+}$ Ions on Si Substrates Journal of Applied Physics 99 (9) 2006: pp. 094105. https://doi.org/10.1063/1.2195368

26. Yuan, G.L., Or, S.W., Liu, J.M., Liu, Z. G.Structural Transformation and Ferroelectromagnetic Behavior in Single-Phase $\mathrm{Bi}_{1-x} \mathrm{Nd}_{x} \mathrm{FeO}_{3}$ Multiferroic Ceramics Applied Physics Letters 89 (5) 2006: pp. 052905. https://doi.org/10.1063/1.2266992

27. Reddy, V.R., Kothari, D., Gupta, A., Gupta, S.M. Study of Weak Ferromagnetism in Polycrystalline Multiferroic Eu
Doped Bismuth Ferrite Applied Physics Letters 94 (8) 2009: pp. 082505.

https://doi.org/10.1063/1.3089577

28. Naganuma, H., Miura, J., Okamura, S. Ferroelectric, Electrical and Magnetic Properties of $\mathrm{Cr}, \mathrm{Mn}, \mathrm{Co}, \mathrm{Ni}, \mathrm{Cu}$ Added Polycrystalline $\mathrm{BiFeO}_{3}$ Films Applied Physics Letters 93 (5) 2008: pp. 0529011-2529013. https://doi.org/10.1063/1.2965799

29. He, Y., Lei, C., Lin, Q., Dong, J., Yu, Y., Wang, L. Mössbauer and Structural Properties of La-Substituted $\mathrm{Ni}_{0.4} \mathrm{Cu}_{0.2} \mathrm{Zn}_{0.4} \mathrm{Fe}_{2} \mathrm{O}_{4}$ Nanocrystalline Ferrite Science of Advanced Materials 7 (9) 2015: pp. 1809-1815. https://doi.org/10.1166/sam.2015.2394

30. Rusakov, V.S., Pokatilov, V.S. Matsnev, M.E., Gubaidulina, T.V. Temperature Investigations of the Spatial Spin-Modulated Structure of Multiferroic $\mathrm{BiFeO}_{3}$ by Means of Mössbauer Spectroscopy Bulletin of the Russian Academy of Sciences Physics 79 (6) 2015: pp. $708-711$. https://doi.org/10.3103/S1062873815060271

31. Wang, K.F., Liu, J.M., Ren Z.F. Multiferroicity, The Coupling Between Magnetic and Polarization Advances in Physics 58 (4) 2009: pp. $321-448$. https://doi.org/10.1080/00018730902920554

32. Lv, H., Zhang, H., Zhang, B., Ji, G., He, Y., Lin, Q. Proposed Electron Transmission Mechanism Between $\mathrm{Fe}^{3+} / \mathrm{Co}^{2+}$ and $\mathrm{Fe}^{3+} / \mathrm{Fe}^{3+}$ in Spinel Structure and its Practical Evidence on Quaternary $\mathrm{Fe}_{0.5} \mathrm{Ni}_{0.5} \mathrm{Co}_{2} \mathrm{~S}_{4}$ Journal of Materials Chemistry C 4 (23) 2016: pp. 5476-5482. https://doi.org/10.1039/C6TC01695B

33. Takahashi, K., Tonouchi, M. Influence of Manganese Doping in Multiferroic Bismuth Ferrite Thin Films Journal of Magnetism and Magnetic Materials 310 (2) 2007: pp. $1174-1176$. https://doi.org/10.1016/j.jmmm.2006.10.280

34. Phokha, S., Pinitsoontorn, S., Rujirawat, S., Maensiri, S. Polymer Pyrolysis Synthesis and Magnetic Properties of $\mathrm{LaFeO}_{3}$ Nanoparticles Physica $B \quad 476$ 2015: pp. 55-60. https://doi.org/10.1016/j.physb.2015.07.021 